\title{
A Longitudinal Study of Dynamic Changes in and Contributing Factors of Learner Belief of Chinese Foreign Language Learners
}

\author{
Xinmiao Liu $^{1}$ \\ ${ }^{1}$ School of English for Specific Purposes, Beijing Foreign Studies University, Beijing, China \\ Correspondence: School of English for Specific Purposes, Beijing Foreign Studies University, Beijing, 100089. \\ E-mail: xinmiaoliu@hotmail.com
}

Received: May 8, 2018 Accepted: June 6, 2018 Online Published: June 8, 2018

doi: 10.5539/elt.v11n7p61 URL: http://doi.org/10.5539/elt.v11n7p61

\begin{abstract}
A longitudinal study was conducted to assess changes in and contributing factors of learner belief for a sample of 70 Chinese foreign language learners. Foreign language proficiency and learner factors such as learner belief and learning strategy were measured four times at approximately fifty-day intervals. The results show that there were significant changes in self-efficacy belief, belief about learning difficulty and belief about learning strategy. The major contributing factors to changes in self-efficacy belief include learning strategy, effort, foreign language anxiety, motivation and foreign language proficiency. Meanwhile, learning style, learning strategy and foreign language anxiety have significant effects on changes in learner belief about learning strategy.
\end{abstract}

Keywords: learner belief, dynamic change, contributing factor

\section{Introduction}

Learner belief is the idea learners hold with regard to learning English as a Foreign Language (EFL). Ever since 1980s, the relationships between learner belief and EFL achievement have been studied extensively (e.g. Wen, 1995; Peacock, 1999; Huang \&Tsai, 2003; Tanaka \& Ellis, 2003), but these efforts have produced mixed results. Some scholars find significant relationships between learner belief and proficiency. For example, Huang and Tsai (2003) compared the beliefs that high achievers and low achievers held about EFL learning and the results revealed significant differences in five areas, namely foreign language aptitude, difficulty in language learning, nature of language learning, learning and communication strategies, and motivation. Wen (1995) found that successful and unsuccessful learners differed significantly in management belief and L1 reliant beliefs. Liu and Dai (2003)'s conclusion, however, is slightly different. They found no significant difference in either self-management belief or L1 reliant belief. Instead, two groups differed considerably in the belief concerning cultural studies, relationship between EFL learning and professional learning, form and function of language and self-evaluation of English proficiency. Tanaka and Ellis (2003) examined the relationship between learner belief and learning outcome and found no significant relationship between the two. This finding is divergent from the results of all the studies discussed above.

One possible explanation for the equivocal evidence is that learner belief is largely perceived as a static trait in much of the research. In reality, learner belief is highly interactive with other learner factors and adaptive to the external environments. However, most studies examined learner belief only at a particular point in time, ignoring their developmental and dynamic nature. Previous research might unveil different parts of the belief continuum, but a more comprehensive picture has not yet emerged.

Another reason for the divergent results is that the interaction of learner belief and other variables (such as anxiety) is largely ignored. Most previous studies focused on situational factors such as course type and EFL classroom. However, individual differences such as learning style and motivation might also lead to changes in learner belief. Therefore, other learner factors need to be taken into consideration to account for changes in learner belief. Besides, most prior studies adopted correlation methods, regardless of what analytical procedures were used. The fact is ignored that predictors need to be temporally precedent of dependent variables in order for causal relationships to be established.

In this study, learner belief is perceived as a dynamic variable which interacts with other learner factors such as foreign language anxiety. This research intends to examine the changing patterns of learner belief and 
contributing factors of these changes using a cross-lagged longitudinal design.

\section{Literature Review}

\subsection{Learner Belief}

Learner belief is "a proposition which may be consciously or unconsciously held, is evaluative in that it is accepted as true by the individual, and is therefore imbued with emotive commitment; further, it serves as a guide to thought and behavior"'(Borg, 2001: 186).Yang (1999) identified four factors constituting learner belief, namely self-efficacy belief, belief about nature and value of language learning, perception of foreign language aptitude and belief about formal structural studies (i.e., learners' perception of the effectiveness of form practice strategies). He proposed that the first two factors constitute motivational belief and last two factors constitute metacognitive belief. Horwitz(1988) classified language learning beliefs into beliefs about foreign language aptitude, beliefs about difficulty of language learning, beliefs about the nature of language learning, beliefs about learning and communication strategy, motivation and expectations. On the basis of the two classifications, we propose that learner belief is composed of self-efficacy beliefs (SEB), beliefs about nature of foreign language learning (BNL), beliefs about foreign language aptitude (BLA), beliefs about difficulty of language learning (BD) and beliefs about learning strategy (BLS). As motivation is considered to be a separate variable in the current study, it is excluded from learner belief to avoid overlapping. The concept of beliefs about formal structural studies in Yang's (1999) classification fails to cover learners' beliefs about other strategy subtypes such as metacognitive strategies, social strategies, affective strategies and compensation strategies. So we deleted this subtype and used instead Horwitz's belief about learning strategy.

\subsection{Contributing Factors of Learner Belief}

Review of previous studies has identified a number of factors that influence learner belief. First, foreign language anxiety is a potential contributor to changes in learner belief. Previous research showed that learners' foreign language anxiety is correlated not only with their beliefs about language learning (Talebinejad \& Nekouei, 2013), but also correlated with their self-efficacy beliefs (Cheng et al., 1999; Ghonsooly \&Elahi, 2011). The amount of stress and anxiety learners experience as they engage in a task influences their perception of their ability to accomplish the task. Learners' feelings of worry or fear about possible unsatisfying performance can undermine their self-efficacy. Many studies have discovered a significant negative association between foreign language anxiety and self-efficacy belief (e.g. Clément et al., 1980; Clément \& Kruidenier, 1985; Kitano, 2001).

Besides, motivation also affects learners' beliefs. Many studies have revealed a close relationship between motivation and learner belief (Gao et al., 2002; Fatemi \& Vahidnia, 2013). An investigation performed by Gao, et al. (2002) discovered that Chinese EFL learners' motivational types are closely related to changes in their self-perception. Motivation is generally found to have a strong effect on self-efficacy in prior literature (e.g., Schunk \& Rice, 1993; Bandura, 1993; Pajares \& Schunk, 2001; Pintrich \& Schunk, 2002). Motivational intensity or effort can also predict learner belief as the intensity of learners' action can shape their understanding of EFL learning as well as their own ability to accomplish a given task.

Learning strategies can have a great influence on learner belief. Ever since 1970s, the relationships between learner belief and learning strategy have been researched extensively and results reveal a significant relationship between the two (e.g. Yang, 1992, 1999; Chang \& Shen, 2010). Learners' experience of using particular learning strategies can result in their reflections on the effectiveness of strategies. Therefore, strategy use can shape learner belief about learning strategies (Yang, 1999).

Another potential contributor is learning style, which is defined as "an individual's natural, habitual and preferred ways of absorbing, processing and retaining new information and skills which persist regardless of teaching methods or content area"(Kinsella, 2002: 171). Learners with different learning styles may perceive language learning differently. For example, learners with social style tend to regard communicative learning strategies as more effective while those with individual learning style might think in a different way. Besides, if visual learners are taught in the way information is presented audibly, they may find it rather difficult to fit in with the incompatible teaching method and consequently may lose confidence. Therefore, learning style can influence learners' perception about learning strategy and self-efficacy.

EFL proficiency was found to have a significant effect on learner belief, especially self-efficacy belief. As Bandura (1986) pointed out, successful experience can enhance individuals' self-efficacy while unsuccessful experience can weaken their self-efficacy. Zhong (2010) also found that improvement in language proficiency can strengthen learners' self-efficacy belief. Learners with a higher level of proficiency are more confident about their ability to have a good command of English. Plenty of studies demonstrated that EFL proficiency and 
self-efficacy belief are closely related with each other (Multon, Brown, \& Lent, 1991; Naseri \& Zaferanieh, 2012; Pajares, 1996, 1997). Therefore, EFL proficiency is a potential contributor to changes in learners' belief, especially in self-efficacy belief.

As discussed above, learner belief is dynamic in nature and constantly influenced by other learner factors. Although it has been investigated in various EFL contexts, given the complex nature of this variable and its relationship with other factors, more efforts are required to explore its specific changing patterns and how it interacts with other variables. The study is especially important to China due to the large number of EFL learners in various learning contexts here. Chinese learners' beliefs vary from person to person and from context to context. Thus, it is essential to examine the changing pattern of learner belief as well as how other factors contribute to learners' individual differences in learner belief among the selected population. It is believed that this research in the Chinese context may provide fresh insights into assumptions about EFL learning which originated primarily from studies in western countries. For these reasons, this study aims to investigate the changing patterns of Chinese college students' learner belief and the major contributors to such changes.

\section{Research Design}

\subsection{Subjects and Procedure}

Seventy Chinese college students were initially recruited for this study and five of them dropped out during the study. The ages of participants ranged from 18 to 22, with a mean of 19.7. All participants were freshman students at the stage of transition from high school to college, a crucial turning point in their life when they were faced with new educational environments. This means that variations in learner factors might be more dramatic, making it more likely to capture changes of learner belief. This longitudinal study spanned over one year. Individual difference factors (learner belief, foreign language anxiety, motivation, learning strategy, effort, learning style) and EFL proficiency were measured four times at a regular interval of fifty days. Participants were required to take proficiency tests in class. To avoid a perfunctory job, they were allowed to finish questionnaires at home and questionnaires were collected within a week after distribution.

\subsection{Measures}

An individual difference questionnaire was developed to measure learner belief, motivation, learning strategy, effort, learning style and foreign language anxiety. The questionnaire was composed of six subscales measuring the six variables. Responses were given on a 5-point Likert scale and all questions were presented in Chinese, participants' native language. Due to the large number of variables in this study and high frequency of measurements, a more concise questionnaire was needed to facilitate implementation. Therefore, researchers minimized overlapping items to allow for easier administration. The questionnaire was piloted with 40 students and revised to ensure high internal consistency before it was used in the survey.

The measure of learner belief was formulated on the basis of the Beliefs about Language Learning Inventory (BALLI) (Horwitz, 1987). 23 items were borrowed from BALLI and nine items were self-developed to fit in with the current conceptual framework. Foreign language anxiety was measured with fifteen items developed on the basis of the Foreign Language Classroom Anxiety Scale (Horwitz, 1985). The anxiety scale was devised to measure test anxiety, communication apprehension and fear of negative evaluation. The measurement of motivation is adapted based on the motivation questionnaire developed by Gao et al. (2003) and the Attitude/Motivation Test Battery (AMTB) (Gardner \& Lambert, 1972; Gardner, 1985). Six questions were chosen from Gao et al.'s (2003) questionnaire and six from AMTB. In addition, six items were self-developed to fit the Chinese EFL contexts. The motivation subscale intends to measure integrative motivation, instrumental motivation and attitude toward EFL learning. Effort was measured with a questionnaire devised on the basis of AMTB. Seven items were chosen from AMTB to measure perseverance and determination and one was added to measure the average length of time spent on EFL learning. Learning strategy measure was based on the Strategy Inventory of Language Learning (SILL) (Oxford, 1990). Fourteen items were borrowed from SILL and nine items were self-developed to measure affective strategy, cognitive strategy, metacognitive strategy and social strategy. For the measure of learning style, seven items were borrowed from the Perceptual Learning-Style Preference Questionnaire (Reid, 1987) and five items were self-developed to measure tactile style, visual style, audio style and kinesthetic style. The internal consistency reliability (i.e., Cronbach's alpha) is $.83, .89, .82, .71, .83$ and .78 for anxiety scale, motivation scale, strategy scale, effort scale, learning style scale and belief scale respectively.

The instruments used to assess proficiency were IELTS test papers published online but new to participants. Two native speakers, one experienced IELTS interlocutor and the other an IELTS assessor, evaluated participants' performance in the oral and writing sections. 


\subsection{Data Analysis}

Cross-lagged regression analysis was conducted to test whether learning strategy, motivation, effort, learning style, foreign language anxiety and EFL proficiency contribute to changes in learner belief. Cross-lagged regression analysis was performed with five learner factors and proficiency as independent variables and belief subtypes and questionnaire items as dependent variables to explore possible contributing factors to changes in learner beliefs.

\section{Results}

\subsection{Variation of Learner Belief}

Results of repeated measure ANOVA suggest that the overall level of learner belief is relatively stable with no significant changes detected at any time interval. Among belief subtypes, there is no significant change in beliefs about learning strategies, nature of language learning or language aptitude over the three time intervals, which indicates that the three belief subtypes are relatively stable over the first school year. There is significant difference in the mean scores for beliefs about difficulty of language learning between Time 1 and Time 2 . The mean scores for self-efficacy beliefs increase significantly from Time 1 to Time 2 and from Time 2 to Time 3 , which means that learners are more convinced about their ability to learn a foreign language. They become more confident than they used to be. Learner beliefs about language learning difficulty significantly go downward from Time 1 to Time 2, which shows that as learners proceed with English learning, they perceive English to be less difficult. To sum up, among all belief subtypes, beliefs about learning difficulty and self-efficacy are relatively more modifiable than other subtypes. Other types of learner beliefs remain largely stable.

Learner belief about learning difficulty declined from 2.68 to 2.60 from Time 1 to Time 2, which shows that learners considered language learning to be less difficult at the end of the first semester at college than upon entering college. Overall self-efficacy beliefs increased from 2.40 to 2.50 from Time 1 to Time 2 and further increased to 2.75 at Time 3 . The finding shows that learners became more convinced about their own ability to learn English well during the first semester. Changes in beliefs about learning strategies, nature of language learning and language aptitude are minute and negligible.

The overall changing pattern of learner beliefs might not be consistent with that of specific items as changes in different items may offset each other, resulting in insignificant overall changes. Despite the seemingly stable pattern identified in certain types of learner belief, subtle changes might occur in specific belief items. Consequently, it is necessary to look into the changing patterns of specific belief items as well.

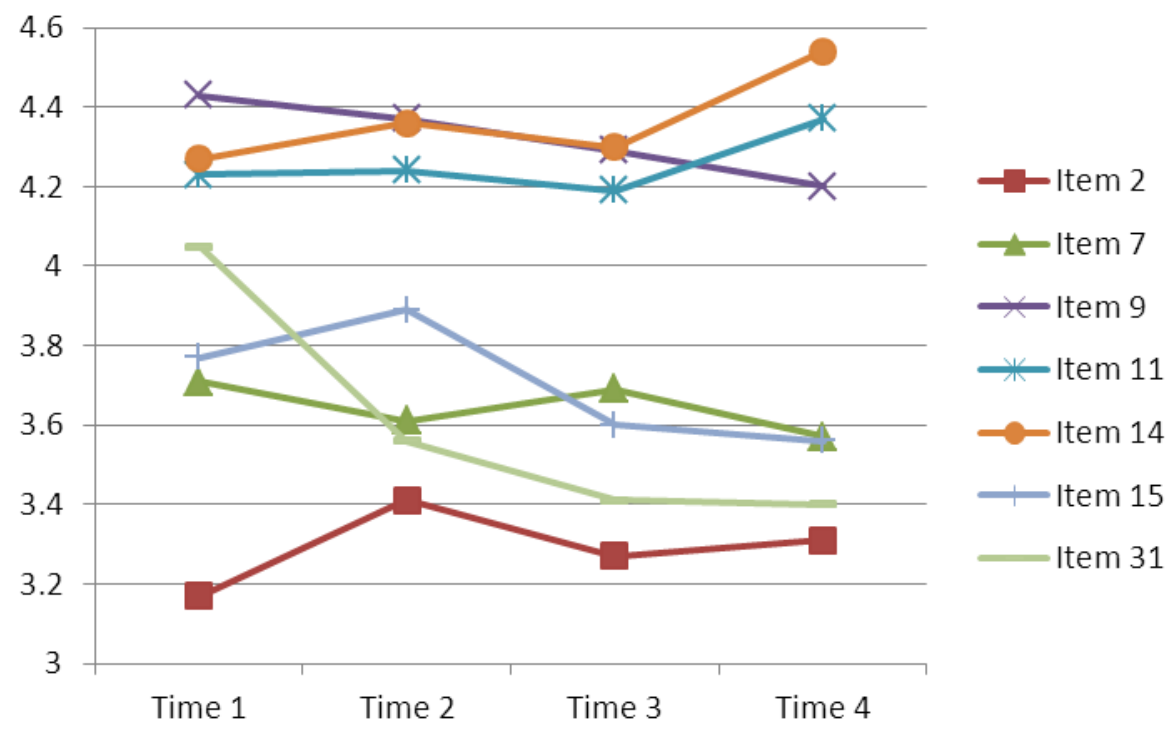

Figure 1. Changing patterns of specific belief items

Results show that five items $(2,11,14,15$ and 31$)$ display significant variation during the fifty-day intervals. The mean score of item 2 ("I have exceptional ability to learn English") increases significantly from Time 1 to Time 2.This increase indicates that learners are more convinced about their ability to master the foreign language after 
they have learned English for the first semester: they develop stronger belief in their ability to learn English well. It remains relatively stable for the other two time intervals. Besides, item 11, 14 and 15, which all measure learners' beliefs about learning strategy, change significantly. The mean score for item 11 ("Using English for daily communication is conducive to English learning") increases significantly from Time 3 to Time 4. This shows that in the second semester, learners increasingly realized the importance of using English for communicative purposes. Item 14 ("reading extensively is conducive to English learning") also displayed significant change from Time 3 to Time 4. This finding shows that learners put greater emphasis on extensive reading in the second semester. The mean score for item 15 ("intensive reading is very important for learning a foreign language") also increases significantly from Time 2 to Time 3, which suggests that learners are more aware of the importance of intensive reading after they have learned English for the first semester at college. Item 31 is associated with the difficulty of learning a foreign language. The mean score decreases significantly from Time 1 to Time 2. This variation indicates that learners considered English learning to be less difficult after the first semester of learning at college.

Besides, item 7 and 9 changed significantly from Time 1 to Time 4, which indicates that although they changed at a much slower pace, significant changes were witnessed on a long term basis. Item 7 ("Associating words with their images is a good method of memorization") declined significantly from Time 1 to Time 4, indicating learners show gradually less approval for this learning approach. Item 9 ("It is necessary to practice pronunciation frequently") declined from 4.43 at Time 1 to 4.20 at Time 4, indicating that learners regarded pronunciation to be less important at the end of the first school year. Figure 2 offers a schematic presentation of changes in the seven belief items.

\subsection{Contributing Factors to the Variation of Learner Belief}

Analysis above shows that among belief subtypes and items, self-efficacy belief, belief about learning difficulty and learners' response to seven items changed significantly. Cross-lagged regression analysis was also performed to explore possible contributing factors to changes in learner belief.

The results of cross-lagged analysis with foreign language anxiety as predictors and learner belief as outcome show that test anxiety and fear of negative evaluation measured at Time 2 had negative effects on changes in self-efficacy belief between Time 2 and Time $3(\beta=-.173, p<.05, \beta=-.175, p<.05)$, which shows that learners who are worried about testing taking or being negatively evaluated by others tend to be less confident in their ability to learn English well. With the decrease in these two types of anxiety, learners' self-efficacy beliefs tend to boom. Among specific items, items 7 and 11 are influenced by foreign language anxiety $(\beta=.255, p<.05, \beta=.262, p<.05)$. Test anxiety has a significant effect on item 7 ("To memorize new words, one must read and write them repeatedly"), which indicates that learners with a higher level of test anxiety have greater preference for rote learning. With the decline of test anxiety, they are more likely to abandon this learning approach. Communication apprehension and fear of negative evaluation also contribute to changes in item 11 ("Using English for daily communication is conducive to English learning") from Time 3 to Time 4 ( $\beta=.262, p<.05$, $\beta=-.267, p<.05$ ), which demonstrates that learners with a higher level of communication apprehension and fear of negative evaluation tend to disapprove the learning of English with communicative approaches.

The results of cross-lagged regression analysis with motivation as predictors and learner belief as the outcome show that integrative motivation measured at Time 2 has a significant effect on the change in overall self-efficacy belief from Time 2 to Time $3(\beta=.238, \mathrm{p}<.05)$, indicating the increase in self-efficacy belief can be attributed to integrative motivation. Besides, learners' attitudes toward learning situation contribute to changes in self-efficacy beliefs from Time 2 to Time $3(\beta=.168, \mathrm{p}<.05)$, which suggests that learners with more favorable attitudes towards learning situations tend to develop stronger self-efficacy belief.

Results of cross-lagged analysis with learning strategy and effort as predictors and learner belief as dependent variable show that affective strategy contributes to the change of self-efficacy beliefs from Time 2 to Time 3 $(\beta=.251, p<.05)$, which shows that the more affective strategies learners use, the more confident they become about their ability to learn English well. Changes in self-efficacy beliefs are also influenced by learners' overall level of effort $(\beta=.250, p<.05)$ : with more efforts devoted to English learning, learners tend to become more convinced about their ability to learn English well after one semester's learning at college. Determination, perseverance and length of time spent on English learning also influence the change of self-efficacy beliefs with regression coefficients of .207,.234 and $.177(p s<.05)$, respectively. Among all belief items, only item 11 ("Using English for daily communication is conducive to English learning") is significantly affected by metacognitive learning strategy $(\beta=.261, \mathrm{p}<.05)$. The other six items are not affected by learning strategy or effort. These results indicate that learning strategy and effort mainly affect self-efficacy beliefs. 
Results of cross-lagged regression analysis with learning style as predictors and learner belief as the outcome show that the change in self-efficacy belief from Time 2 to Time 3 is influenced by kinesthetic learning style $(\beta=.188, \mathrm{p}<.05)$, which suggests learners with a kinesthetic style are more inclined to develop stronger self-efficacy belief. Analysis on the specific belief items show that only item 11 ("Using English for daily communication is conducive to English learning") is significantly influenced by learning style $(\beta=-.271, p<.05)$. The tactile style has a significant positive effect on changes in item 11 from Time 3 to Time 4 , which suggests that the more the learners prefer to learn through handling or manipulating resources, the less preferences they have for communicative learning approaches.

To test whether EFL proficiency is a causal factor for changes in learner belief, we performed regression with learner belief as the outcome and proficiency as the predictor. The results indicate that belief about learning difficulty is not influenced by proficiency during any time interval. This suggests that proficiency is not a major contributor to this factor. The overall level of proficiency and speaking proficiency have significant effects on the change in self-efficacy beliefs $(\beta=.106, \mathrm{p}<.05, \beta=.204, \mathrm{p}<.05)$, which shows that, with the improvement of learners' proficiency, especially speaking proficiency, they tend to have stronger self-efficacy. Proficiency also influences the change in learners' perception about rote learning $(\beta=-.311, p<.05)$, which indicates that as learners' overall language proficiency improves, they prefer to use fewer rote learning strategies. Listening proficiency and writing proficiency have significant negative effects on their perception of communicative learning $(\beta=-.224, p<.05, \beta=-.190, p<.05)$, which indicates that, with the enhancement of learners' listening and writing proficiency, they become less convinced that communicative approach is conducive to EFL learning.

\section{Discussion}

\subsection{Changing Pattern of Learner Belief}

Results of the present study show that the mean score for overall learner belief did not change significantly during the period under study, which shows that learner belief is a relatively stable variable, a result that is consistent with findings in previous literature (e.g. Furnham et al., 1985; Langston \& Sykes, 1997). The finding further confirms the previous understanding of beliefs as "stable mental representations that are fixed a-priori constructs" (Kalaja \& Barcelos, 2003: 2). Learner beliefs are formulated through learners' long-term interaction with their learning environment. Past experience plays a crucial role in constructing and shaping learners' beliefs. Just as Little and Singleton (1990) pointed out, learner beliefs reflect the nature of the instruction learners have experienced. Once constructed, beliefs become rather stable and static. They are the preconceptions that were constructed at the initial stage of EFL learning and brought into EFL learning at college. Therefore, it is unlikely for learner belief to change abruptly or randomly. However, this does not mean learner belief has never changed. The present study found that, although learner belief did not display dramatic overall changes, significant changes are still going on in specific belief components and subcomponents. Self-efficacy belief increased significantly and continuously during the first semester and remained relatively stable during the second semester. The change in self-efficacy belief mainly occurred before the beginning of the second semester, which shows that the first semester seems to be the critical period for building up learners' self-efficacy beliefs. Teachers should give students more emotional supports and assistance to boost their confidence in the first semester at college because, as this study shows, steps taken at this stage tend to be more effective. Belief about learning difficulty declined from Time 1 to Time 2, which shows that learners perceived English learning to be less difficult at the end of the first semester than at the beginning.

\subsection{Contributing Factors of Learner Belief}

The finding suggests that learner belief is connected with other learner factors and EFL proficiency in a complex way. Among the six learner factors, learning strategy, effort and language proficiency are the major sources of influence on learner belief. Learners' use of affective learning strategies contributes significantly to changes in learners' self-efficacy belief. The finding is consistent with previous studies that established connections between self-efficacy belief and affective strategy (Abbas \& Mahboubeh, 2015). This is because learners who use affective strategies to manage and control their emotions are more capable of developing stronger self-efficacy. The finding highlights the importance of providing affective strategy instruction in the first semester as it might be an effective approach to boosting learners' self-efficacy.

Effort influences the variation of self-efficacy belief as well. The students who spend longer time on EFL learning or who are more persistent and determined to learn English are more assured about their capability to accomplish EFL tasks. This finding indicates that effort can produce a positive effect on EFL learners' self-perception. This is because greater efforts usually result in better learning outcome, which will in turn promote greater self-efficacy among learners. As previous studies generally show that a heightened sense of 
self-efficacy is a strong source of EFL task engagement (Schunk, 1983), the relationship between self-efficacy and effort might be reciprocal.

Foreign language anxiety is found to be a significant contributor to changes in self-efficacy belief. Among three anxiety subtypes, fear of negative evaluation and test anxiety have great effects on self-efficacy belief in the second semester. This is easy to understand as learners who are worried about taking test and who are afraid of being negatively evaluated are not quite convinced that they can learn English well. With the level of the two anxiety subtypes going down, learners' self-efficacy grows stronger. Results indicate that anxiety alleviation may have a positive impact on learners' self-efficacy. The result is in line with Truiit (1995)'s research, which also found that EFL learners with a higher level of anxiety tend to have lower self-efficacy. Among the belief items, item 7 and item 11 are influenced by foreign language anxiety. Test anxiety has a positive effect on the change in learners' perception of rote learning strategy. Learners with a higher level of anxiety give greater support to rote learning. As their anxiety goes down, they would abandon the use of this strategy. It might be because learners who are worried about taking tests tend to resort to repeated reading and writing to reinforce their memory of vocabulary with the aim of improving their test performance. Communication apprehension has a positive effect on the change in learners' belief about communicative learning strategy. This indicates that even if learners feel frightened or anxious during EFL communication, they still regard communication as an effective way to EFL learning. Communication apprehension may inhibit learners' communicative behaviors, but it does not prevent learners from developing appropriate beliefs about communicative learning. Apart from that, fear of negative evaluation also has significant negative effect on the change in item 11, which suggests that as learners are less worried about being negatively evaluated, they regard communicative learning to be more effective. The possible reason is that the reduction in fear of negative evaluation gives learners more courage to engage in oral communications and consequently, they can better appreciation the effectiveness of this learning approach.

Among the different learning styles, tactile style and kinesthetic style contribute to variation in learner belief. The more the learners prefer to learn through body movement, the stronger self-efficacy belief they will develop. The other styles have no significant effect on self-efficacy beliefs. Tactile style has a negative influence on the change in item 11 ("Using English for daily communication is conducive to English learning"). As learners develop stronger preference for learning through hand-on activities, they react less favorably towards communicative learning. This might be related to incompatibility between tactile style and communicative learning in EFL classrooms. Tactile learners like to learn English through manipulating resources with hands. However, communicative learning in EFL classrooms involves few hand-on activities and thus can seldom be well received by tactile learners.

EFL proficiency can also significantly predict changes in learner belief. EFL proficiency, especially speaking proficiency, has a strong influence on learners' self-efficacy belief, which is consistent with Dodds (2011)'s finding that speaking proficiency and self-efficacy belief are significantly correlated. This finding is logically correct as learners with better speaking competence tend to be more self-assured about accomplishing learning tasks. Maddux and Gosselin (2012) identified five sources of self efficacy: performance experience, vicarious experience, imaginal experience, verbal persuasion, and affective and physiological states. Among the five sources, as Bandura $(1977,1997)$ pointed out, performance experience is the most important and powerful source of self-efficacy beliefs. Learners' belief about whether they are able to handle a task is closely associated with their past attempt to deal with similar tasks. Successful past attempts will reinforce learners' beliefs in themselves while failed attempts may result in diminishing self-efficacy. Besides, changes in learner's proficiency level also affect their perception of the effectiveness of learning strategies. Listening speaking and writing proficiency have negative effects on the change in item 11("Using English for daily communication is conducive to English learning"). This is because learners tend to switch to other approaches to EFL learning when their listening and writing ability improved. Overall proficiency has a negative effect on item 7 ("To memorize new words, one must read and write them repeatedly"). With the improvement in learners' proficiency, they will abandon rote learning approaches featured by repeated reading and writing. This finding has been supported by Samian's study (2012) which shows that learners with a high level of proficiency use fewer rote learning strategies than their low-proficiency counterparts.

Integrative motivation and attitudes toward learning situations have significant effects on the change in self-efficacy belief from Time 3 to Time 4. Integrative motivation has a positive effect on learners' self-efficacy beliefs, which shows that learners with stronger integrative motivation are more inclined to develop self-efficacy during the second semester. The finding suggests that it might be an effective way to boost learners' self-efficacy by cultivating their interests in foreign language and culture or encouraging them to be more engaged in foreign language communities in the second semester at college. Attitudes toward learning situations have a positive 
effect on self-efficacy beliefs, which shows that learners' attitudes toward EFL teachers, EFL class and teaching methodology will influence their perception of their own language learning ability. The more favorable their attitudes are, the more they are convinced they can learn the language well. One possible reason is that learners believe that a good language learning environment is the prerequisite for mastering a foreign language. As a result, the learners satisfied with the external conditions tend to be more optimistic and confident about their own learning outcome.

\section{Conclusion}

The one-year longitudinal study showed that changing patterns of learner belief are rather complex, with belief components displaying different changing trajectories. Significant changes were witnessed in self-efficacy belief, belief about learning difficulty and learners' response to seven questionnaire items measuring self-efficacy belief and belief about learning strategy. The major contributing factors to changes in self-efficacy belief include affective strategy, effort, foreign language anxiety, motivation and EFL proficiency. Kinesthetic style, metacognitive strategies and all three types of foreign language anxiety have significant effects on changes in belief about learning strategy. No factor is found to contribute to changes in belief about learning difficulty. The study provides us a better understanding of learner belief so that teaching and learning can be tailored to EFL learners' individual differences. However, certain limitations exist due to various constraints. The study followed seventy Chinese learners for one school year. However, it may take longer for learner belief to display more significant changes. Our failure to capture significant changes in many belief components such as belief about the nature of language learning and belief about language aptitude may be due to the relatively short research span. Extending the length of time intervals between two measurements might enable us to find more interesting changing patterns in learner belief.

\section{Acknowledgements}

This study is supported by Beijing Social Science Fund (16YYC032), the Fundamental Research Funds for the Central Universities (ZJ1605) and Xuguozhang Language Senior Academy in Beijing Foreign Studies University.

\section{References}

Abbas, A. Z. \& Mahboubeh, G. (2015). Self-efficacy as a Function of Language Learning Strategy Use. British Journal of Education, Society \& Behavioural Science, 9(3), 223-235. https://doi.org/10.9734/BJESBS/2015/18735

Bandura, A. (1977). Self-efficacy: Toward a unifying theory of behavioral changes, Psychological Review, 84, 191-215. https://doi.org/10.1037/0033-295X.84.2.191

Bandura, A. (1993). Perceived self-efficacy in cognitive development and functioning. Educational Psychologist, 28(2), 117-48. https://doi.org/10.1207/s15326985ep2802_3

Bandura, A. (1997). Self-efficacy: The Exercise of Control. New York: Freeman.

Borg, M. (2001). Key concepts in ELT. Teachers' Beliefs. ELT Journal, 55(2), 186-187. https://doi.org/10.1093/elt/55.2.186

Chang, C. Y., \& Shen, M. C. (2010). The effects of beliefs about language learning and learning strategy use of junior high school EFL learners in remote districts. Research in Higher Education Journal, 8.

Cheng, Y.-S., Horwitz, E. K., \&Schallert, D. L. (1999). Language anxiety: Differentiating writing and speaking components. Language Learning, 49, 417-446. https://doi.org/10.1111/0023-8333.00095

Clément, R., Gardner, R. C., \& Smythe, P. C. (1980). Social and individual factors in second language acquisition. Canadian Journal of Behavioural Science, 12, 293-302. https://doi.org/10.1037/h0081081

Clément, R., \& Kruidenier, B. G. (1985). Aptitude, attitude and motivation in second language proficiency: A test of Clément's model. Journal of Language and Social Psychology, 4(1), 21-37. https://doi.org/10.1177/0261927X8500400102

Dodds, J. (2011). The correlation between self-efficacy beliefs, language performance, and integration amongst Chinese immigrant newcomers. MA dissertation. Hamline University, Saint Paul, Minnesota.

Fatemi, A. H. \&Vahidnia, F. (2013). Self-efficacy and Motivation among Iranian EFL Learners: An Investigation into their Relationships, International Journal of English Language Education, 1(3), 79-89.

Furnham, A., Johnson, C., \& Rawles, R. (1985). The determinants of beliefs in human nature. Personality and Individual Differences, 6(6), 675-684. https://doi.org/10.1016/0191-8869(85)90078-9 
Gao, Y., Zhao, C., Cheng, Y., \& Zhou, Y. (2002). Relations between motivation types of Chinese college undergraduates and the changes in self-identity, Foreign Language Teaching, 4, 18-24.

Gardner, R. C., \& Lambert, W. E. (1972). Attitudes and Motivation in Second Language Learning. Rowley: Newbury House Publishers.

Gardner, R. C. (1985). Social Psychology and Second Language Learning: The Role of Attitudes and Motivation. London: Edward Arnold.

Ghonsooly, B., \& Elahi, M. (2011). Learners' Self-efficacy in Reading and its relation to Foreign Language Reading Anxiety and Reading Achievement. Journal of English Language Teaching and Learning, 53.

Huang, S. C., \& Tsai, R. R. (2003). A comparison between high and low English proficiency learners' beliefs. ERIC Document. Retrieved from https://eric.ed.gov/?id=ED482579

Horwitz, E. K. (1985). Surveying student beliefs about language learning and teaching in the foreign language $\begin{array}{llll}\text { methods course, Foreign } \quad \text { Language } & \text { Annals, }\end{array}$ https://doi.org/10.1111/j.1944-9720.1985.tb01811.x

Horwitz, E. K. (1987). Surveying student beliefs about language learning. In A. Wenden, \& J. Rubin (Eds.), Learning Strategies in Language Learning (pp. 119-129). Englewood Cliffs, NJ: Prentice-Hall.

Horwitz, E. K. (1988). The beliefs about language learning of beginning university foreign language students. Modern Language Journal, 72, 283-294. https://doi.org/10.1111/j.1540-4781.1988.tb04190.x

Kalaja, P., \& Barcelos, A. M. F. (2003). Introduction. In P. Kalaja, \& M. F. Barcelos (Eds.), Beliefs about SLA: New Research Approaches (pp. 1-4). Dordrecht: Kluwer. https://doi.org/10.1007/978-1-4020-4751-0

Kinsella, K. (2002). Understanding and empowering diverse learners in ESL classrooms. In J. M. Reid (Ed.), Learning Styles in the ESL/EFL Classroom (pp. 170-194). Beijing: Foreign Language and Teaching Research Press.

Kitano, K. (2001). Anxiety in the college Japanese language classroom. Modern Language Journal, 85, 549-566. https://doi.org/10.1111/0026-7902.00125

Langston, C. A., \& Sykes, W. E. (1997). Beliefs and the Big Five: Cognitive bases of broad individual differences in personality. Journal of Research in Personality, 31, 141-165. https://doi.org/10.1006/jrpe.1997.2178

Little, D., \& Singleton, D. (1990). Cognitive style and learning approach. In R. Duda \& P. Riley (Eds.).Learning Styles. France: Presses Universitaires de Nancy.

Liu, R., \& Dai, M. (2003). Current Situations of EFL Teaching Reform among Chinese Universities and Development Strategies. Beijing: Foreign Language Teaching and Research Press.

Maddux, J. E., \& Gosselin, J. T. (2012). Self-efficacy. In M. R. Leary, \& J. P. Tangney (Eds.), Handbook of Self and Identity (pp. 218-238). New York: Guilford.

Multon, K. D., Brown, S. D., \& Lent, R. W. (1991). Relation of self-efficacy beliefs to academic outcomes: A $\begin{array}{lllll}\text { meta-analytic investigation. Journal of Counseling Psychology, 38, 38. } & \text { 38 }\end{array}$ https://doi.org/10.1037/0022-0167.38.1.30

Naseri, M., \& Zaferanieh, E. (2012). The Relationship Between Reading Self-efficacy Beliefs, Reading Strategy Use and Reading Comprehension Level of Iranian EFL Learners, World Journal of Education, 2(2).

Oxford, R. L. (1990). Language Learning Strategies: What Every Teacher Should Know. New York: Newbury House Publishers.

Pajares, F. (1996). Self-efficacy beliefs in academic settings. Reviews of Educational Research, 66, 543-578. https://doi.org/10.3102/00346543066004543

Pajares, F. (1997). Current directions in self-efficacy research.In M. Maeher, \& R. P. Pintrich. (Eds.), Advances in Motivation and Achievement (pp. 1-49). Greenwich, CT: JAI.

Pajares, F., \&. Schunk, D. H. (2001). Self-beliefs and school success: Self-efficacy, self-concept, and school achievement. In R. Riding and S. Rayner. (Eds). Perception (pp. 239-66). London: Ablex Publishing.

Peacock, M. (1999). Beliefs about language learning and their relationship to proficiency. International Journal of Applied Linguistics, 9(2), 247-263. https://doi.org/10.1111/j.1473-4192.1999.tb00175.x

Pintrich, P. R., \& Schunk. D. H. (2002). Motivation in education: Theory, research, and applications (2nd ed.). 
Englewood Cliffs, NJ: Prentice Hall.

Reid, M. J. (1987). The learning style preferences of ESL students. TESOL Quarterly, 21(1), 87-111. https://doi.org/10.2307/3586356

Richards, J. C., Schmidt, R., Kendrick, H., \& Kim, Y. (2005). Longman Dictionary of Language Teaching and Applied Linguistics (3rd Ed.). Beijing: Beijing Foreign Language Teaching and Research Press.

Samian, S. H. (2012).The Relationship between Iranian EFL Learners' Rote Learning Strategy Use and Their Level of Proficiency, Journal of Language Teaching and Research, 3(4), 625-631. https://doi.org/10.4304/jltr.3.4.625-631

Schunk, D. H. (1983). Ability versus effort attributional feedback: Differential effects on self-efficacy and achievement. Journal of Educational Psychology, 75, 848-856. https://doi.org/10.1037/0022-0663.75.6.848

Schunk, D. H., \& J. M. Rice. (1993). Strategy fading and progress feedback: Effects on self-efficacy and comprehension among students receiving remedial reading services. Journal of Special Education, 27, 257-76. https://doi.org/10.1177/002246699302700301

Talebinejad, M. R., \&Nekouei, R. (2013). The relationship between foreign language anxiety and belief toward FLL among children EFL learners. Basic Research Journal of Education Research and Review, 2(3), 49-54.

Tanaka, K., \& Ellis, R. (2003). Study abroad, language proficiency, and learner beliefs about language learning. JALT Journal, 25, 63-85.

Wen, Q. (1995). Differences in learning methods between successful and unsuccessful EFL learners (trans.). Foreign Language Teaching and Research, 3.

Yang, N. (1992). Second language learners' beliefs about language learning and their use of learning strategies: A study of college students of English in Taiwan. Unpublished doctoral dissertation. The University of Texas, Austin, TX.

Yang, N. D. (1999).The relationship between EFL learners' beliefs and learning strategy use. System, 27(4), 515-535. https://doi.org/10.1016/S0346-251X(99)00048-2

Zhong, Q. (2010). The Effect of Chinese ESL Learners' Beliefs on their Autonomous Learning. Studies in Self-Access Learning Journal, 1(3), 212-225.

\section{Copyrights}

Copyright for this article is retained by the author(s), with first publication rights granted to the journal.

This is an open-access article distributed under the terms and conditions of the Creative Commons Attribution license (http://creativecommons.org/licenses/by/4.0/). 